\title{
Impact of Social Distancing on the Mental Health of Parents and Children in Qatar
}

\author{
Mohamed Abdelrahman ${ }^{1}$ (D) - Duaa Al-Adwan ${ }^{2} \cdot$ Youssef Hasan $^{3}$
}

Accepted: 24 May 2021 / Published online: 7 June 2021

(C) The Author(s), under exclusive licence to Springer Science+Business Media, LLC, part of Springer Nature 2021

\begin{abstract}
This study investigated the effects of COVID-19-related social distancing practices on parents and children's mental health and explored joint parent-child activities and coping strategies among Arab families in Qatar. The sample of 308 parents answered selfreported questionnaires regarding their mental health, coping strategies, activities with their children, social distancing practices, and their children's mental health. Pearson's correlation coefficient and structural equation modeling were carried out. The results showed a significant positive correlation between social distancing and parents' activities with their children and their coping strategies, as well as between parents' mental health, activities with their children, children's mental health, and parents' coping strategies. Path analysis showed that social distancing practices influence both parents' and children's mental health through parents' activities with children and their coping strategies. Our findings revealed how living under stressful conditions, such as COVID-19, could enhance the mental health of family members.
\end{abstract}

Keywords Social distancing · COVID-19 · Coping strategies $\cdot$ Parent mental health $\cdot$ Children's mental health · Family mental health

Since December 2019, the world has been experiencing a global health crisis due to the novel coronavirus disease (COVID-19). According to the World Health Organization (WHO), the novel virus (named SARS-CoV-2) seems closely related to the known coronaviruses. Its outbreak has been reported to possibly be related to the sale of meat derived from wild or captive sources in a seafood market in Wuhan, Hubei province, China (Cui et al., 2019).

During the past few months, there was a significant increase in mortality and morbidity due to COVID-19. To date (October 15, 2020), more than 38 million cases and 1 million deaths

Mohamed Abdelrahman

mkk.abdelrahman@gmail.com

1 Mokhtass for Consultations and Research, Ahmed Bin Mohamed Bin Thani, Doha, Qatar

2 Applied Science Private University, Amman, Jordan

3 Qatar University, Doha, Qatar 
have been reported in 235 countries (World Health Organization, 2020). The COVID-19 pandemic has caused many economic losses, reduced physical interaction, and significant psychological distress (Remuzzi \& Remuzzi, 2020).

Torales et al. (2020) discussed the impact of the pandemic on mental health and reviewed previous experiences of epidemics and social isolation. According to the WHO, social distancing is an important strategy to combat the spread of the virus and to avoid overburdening healthcare systems. Since the start of the pandemic, strict lockdown and imposed social distancing measures - keeping a physical distance of no less than one and a half meter between people to prevent infection (Nanshan et al., 2020) - have been enacted to control the spread of COVID-19 (Wilder \& Freedman, 2019). These measures are implemented to avoid or reduce contact between individuals possibly infected with the pathogen, in order to slow down the rate of transmission. This strategy can lead to a decrease in prevalence, morbidity, and mortality due to the disease (Lau et al., 2020).

The impact of social distancing on the lives of individuals can range from fear and anxiety to the development of obsessive-compulsive disorders due to fear of infection (Prestia et al., 2020). Moreover, children are also affected by social distancing, as they encounter news about the pandemic on television and social media, while they are also capable of listening in on parents' conversations.

Recent studies have investigated the effects of the COVID-19 pandemic on the daily lives of individuals (e.g., Marroquin et al., 2020; Galea et al., 2020). A study conducted by Jacobson et al. (2020) in the USA analyzed more than 10 million Google searches to assess changes in mental health search queries during the stay-at-home period of the pandemic. Jacobson et al. found that most queries were focused on strategies to deal with anxiety, insomnia, loss of appetite, or thoughts about death and suicide. The effects of social distancing on mental health range from increased attention to injury and the virus' death toll to poor understanding and decreased decision-making abilities, which may hinder control of the epidemic. Moreover, social distancing can have a lasting impact on individuals' overall well-being (Kang et al., 2020). During the past six months of the COVID-19 pandemic, there has been a surge in mental health problems among the general population, including the elderly, children, workers in various sectors, and healthcare professionals (Duan \& Zhu, 2020; Chen et al., 2020a, b; Liem et al., 2020; Yang et al., 2020).

Additionally, since the start of online learning due to the closing of schools, children have become physically less active, spending long periods using electronic devices, and their sleep patterns and eating habits have become disrupted, resulting in weight gain and loss of cardiovascular fitness (Wang et al., 2020a, b). Similar circumstances apply not only to families with children but also to adults and older adults globally (Heckman et al., 2020). Moreover, other direct and indirect effects have been observed, such as the overburdening of parents, with increased obligation to care for and educate their children (Bayham \& Fenichel 2020). After the start of the COVID-19 pandemic in Wuhan, more than 220 million children and adolescent in China were confined to their homes with their parents (Wang et al., 2020a, b). Thus, the authorities have requested that more attention be paid to the mental health of children who are isolated at home (Liu et al., 2020), as they may suffer from fear of infection and feelings of frustration and boredom, as well as lack of accurate and correct information; lack of personal contact with classmates, friends, and teachers; and limited personal space in their home to play outdoor games and activities (Wang et al., 2020a, b). These feelings are in addition to parents' concerns about unemployment and the family's financial losses associated with the spread of COVID-19 (Clemens et al., 2020). 
In Qatar, the government has given much attention to the mental health of children and young people. Government services have been launched to promote the mental health of parents and children. For example, the Hamad Medical Corporation (HMC) and Sidra Medicine have dedicated multi-disciplinary services providing psychological support for parents and children, including adolescents. Considering the prevalence of mental health disorders among children and adolescents (Al-Kaabi et al., 2017), there is a lack of data in this regard.

Many parents experience problems while dealing with their children during the pandemic. Both children and adults feel isolated, while children are not allowed to go play outside their home or meet their peers for fear of infection (Wang et al., 2020a, b). Family members who have lost loved ones due to the pandemic often experience intense feelings of anger and resentment (Goyal et al., 2020) and may feel shame, guilt, or stigma related to family members who are infected or in quarantine (Brooks et al., 2020). A study reported post-traumatic stress disorder and depression among family members, as well as a breakdown in inter-family communication (Christofferson et al., 2020). Another study showed that children who were isolated or whose parents were isolated during the epidemic had a higher chance of developing acute stress disorder, coping disorders, and grief (Shah et al., 2020).

Cui et al. (2020a, b) investigated the most common symptoms manifested by children suffering from major mental health problems, which included the following: disruption of sleeping patterns and eating habits, as well as an inability to communicate with their parents or medical staff. Additionally, children experiencing mental health issues can have mood swings, such as increased aggression, fear, depression, and anxiety (Chen et al., 2020a, b). Moreover, abnormal and unacceptable behaviors, such as refusing treatment and harming medical staff or themselves, have been observed (Chen et al., 2020a, b). Further, some psychotic symptoms have also been reported, including the following: inability to recognize family or friends, strange thoughts, inability to understand others, or visual or auditory hallucinations. Lastly, physical symptoms have also been reported, including the following: feelings of physical discomfort, headaches, or stomach pains without a clear reason (Cai et al., 2020).

During the current pandemic, families must share a limited space inside the house and use any resources available to change their routine and deal with new challenges (Brooks et al., 2020). During social isolation, children require doing things that bring them joy, which need to be balanced with the burdens and concerns of parents (Matsubayashi et al., 2020). Parents' concerns include fear of losing their job, economic burdens, loss of physical and social interaction with extended family, and their responsibility toward their children in helping them express their feelings, thoughts, and fears (Fegert \& Kölch (2017). Under these circumstances, parents are responsible for carrying out activities that enhance and support their own mental health and that of their children (Fegert et al., 2020).

Some studies conducted in China provide suggestions for caring for the mental health of those affected by the pandemic, especially children ( $\mathrm{Zu}$ et al., 2020; Wang et al., 2020a, b). It is important to provide psychological services to both parents and children in order to manage children's behavior, sleep patterns, dietary habits, exercise, and cooperation with parents regarding academic responsibilities (Wilkinson et al., 2008). It is also important to address parents' emotional response to children's anxiety by developing emotional expression and family activities. One study suggests that parents ought to be trained to keep their feelings "stable," especially when managing their children's behavior (Primack et al., 2012).

Since the beginning of the global health crisis caused by COVID-19, Qatar has worked to contain the pandemic by closing schools and government institutions, activating learning and 
working from home, closing shops in markets and malls, and confining shopping to food stores and pharmacies (Ministry of Public Health, 2020). In addition, an intensive awareness campaign including advertisements, as well as social media and television programs, was implemented to inform the citizenry about the disease and to inform them of the most noteworthy developments in health studies and research (Omrani et al., 2020). Furthermore, the government aimed to create awareness of the importance of social distancing practices and the need for citizens to follow preventive health measures, such as wearing masks and gloves and sterilizing surfaces and food (Jones, 2020).

In summary, prior studies have investigated the negative consequences of the COVID-19 pandemic on people's mental health. However, to our knowledge, no studies have explored how parents can employ their skills to maintain good mental health among all family members by helping them develop adequate coping mechanisms and by engaging in family activities.

\section{Study Hypotheses}

COVID-19-related social distancing practices may have influenced parents to develop and engage in activities with their children and to invest their coping skills to mitigate the boredom they may encounter during the long stay-at-home period. This might have allowed families to improve their mental health in isolation. Thus, we hypothesize the following:

1. There will be a significant positive correlation between social distancing practices and parents' activities with their children.

2. There will be a significant positive correlation between social distancing practices and parents' coping strategies.

3. Social distancing practices have a positive impact on the mental health of parents and children through participation in family activities.

\section{Methods}

\section{Participants}

Data were collected via online questionnaires between June 11 and July 10, 2020, using a snowball sampling method. Eligible participants were from Arab families who resided in Qatar. According to Kline (1998), an adequate sample size should be ten times the amount of the items in the path analysis; our proposed model includes 17 items. Therefore, the required sample size was a minimum of 170 participants. A total of 325 participants were recruited using convenience sampling. After recovery of all questionnaires, 17 responses were excluded, as they were incomplete. Thus, the final sample included 308 participants, of which $66.7 \%$ were women. Respondents were parents aged 24-64 years $\left(\mathrm{M}_{\text {age }}=40.90, S D= \pm 10.07\right)$. Regarding their level of education, 95\% of respondents had a college degree or higher. Parents were asked to complete a self-reported questionnaire and a parent-reported questionnaire regarding their children. To ensure consistency between parents' responses to the parent-reported questionnaire, parental units were instructed to discuss each item and to provide a single response. 
Participation was voluntary and respondents were asked to complete the online questionnaire sent to their mobile phones via social network. Approval for this study was obtained from the appropriate institutional review board. Respondents were presented with a clear description of the study, and they provided written informed consent prior to completing the survey.

\section{Measures}

Mental Health Continuum Scale This 14-item scale developed by Keyes (2005) was used after being translated from English to Arabic by the author and back-translated by a professional translator to ensure accuracy and internal consistency. Participants were asked to consider the past month and rate the question items on a five-point Likert scale from 1 (never) to 5 (every day). The items measure emotional well-being (e.g., "How often did you feel interested in life?"), psychological well-being (e.g., "How often did you like most parts of your personality?"), and social well-being (e.g., "How often did you feel that our society is becoming a better place for people?"). A confirmatory factor analysis (CFA) showed the suitability of the scale, where $\chi^{2} / \mathrm{df}=2.19$; RMSEA $=.062$; $\mathrm{SRMR}=.03$; $\mathrm{CFI}=.95$; NFI $=$ .94 ; GFI $=0.94$; and TLI $=.95 .^{1}$ The scale was observed to have good reliability (Cronbach's $\alpha=0.92$ and the inter-item correlation mean $=0.47$ ), while the composite reliability $(\mathrm{CR})$ and average variance extracted (AVE) were acceptable at 0.75 and 0.53 , respectively.

Social Distancing Practices A five-item scale developed by Abdelrahman (2020) was used. Items included questions such as "I do not go outside my home unless it is necessary" and "I keep adequate distance when I communicate with others." Each item was rated on a five-point Likert scale ranging from 1 (never) to 5 (always). To check the model fit and the unidimensional factor structure, a CFA was run and showed that $\chi^{2} / \mathrm{df}=1.25$; RMSEA $=0.03$; SRMR $=$ $0.02 ; \mathrm{CFI}=0.99 ; \mathrm{NFI}=0.99 ; \mathrm{GFI}=0.99$; and $\mathrm{TLI}=.99$. The internal consistency of the scale was acceptable (Cronbach's $\alpha=0.75$, inter-item correlations mean $=0.39$ ) and the $\mathrm{CR}$ and AVE were acceptable $(0.74$ and 0.49 , respectively).

Coping Strategies of Parents We selected and adapted five items from the coping strategies scale developed by Carver (1997), which, according to Garcia et al. (2018), is the best validated measure and is widely used to assess coping strategies. The selection criteria for the items were based on the pandemic context and adapted for Arab culture. Participants were asked to report how they acted when encountering a problematic event. Items were rated on a five-point scale ranging from 1 (never) to 5 (always). The items included "I have been looking to see something good in what is happening" and "I have been accepting the reality of the fact that it has happened." A confirmatory factor analysis revealed the suitability of the factor structure $\left(\chi^{2} / \mathrm{df}=2.24, \mathrm{RMSEA}=0.06, \mathrm{SRMR}=0.03, \mathrm{CFI}=0.98, \mathrm{NFI}=0.97, \mathrm{GFI}=0.98\right.$, and TLI $=0.97$ ). The internal consistency of the scale was deemed to be good (Cronbach's $\alpha=0.80$ and the inter-item correlations mean $=0.44$ ) and the CR and AVE were acceptable at 0.80 and 0.56 , respectively.

Parental Activities with Their Children This scale assesses the level of parents' engagement in activities with their children. We developed four items to describe the actions taken by the

\footnotetext{
${ }^{1}$ Root mean square residuals (RMSEA), standardized root mean square residuals (SRMR), comparative fit index (CFI), normed fit index (NFI), goodness-of-fit index (GFI), Tucker-Lewis index (TLI)
} 
parents to ensure their children's well-being during isolation. Parents were asked to discuss the actions they took and activities they engaged in with their children. The items were rated on a five-point Likert scale ranging from 1 (never) to 5 (always). The items were, for instance, "during our stay at home, we play with our children." An exploratory factor analysis showed that the items formulate one factor and the item loadings $>0.40$, which explains $45 \%$ of the variance. To confirm the scale's validity, a CFA was performed, which showed an acceptable model fit for the unidimensional factor structure $\left(\chi^{2} / \mathrm{df}=0.876\right.$; RMSEA $=0.00$; SRMR $=$ 0.006; $\mathrm{CFI}=0.99 ; \mathrm{NFI}=0.98 ; \mathrm{GFI}=0.99 ; \mathrm{TLI}=0.99$ ). Internal consistency of the scale was good (Cronbach's $\alpha=0.81$; inter-item correlations mean = 0.52) and the CR and AVE were acceptable $(0.73$ and 0.52 , respectively).

Children's Mental Health This tool assesses the levels of depression and anxiety in children. We included eight items taken from the Diagnostic and Statistical Manual of Mental Disorders, four items for each factor. An exploratory factor analysis was performed and showed that the two factors (depression and anxiety) explained $50 \%$ of the variance. A CFA showed that the two-dimensional structure had a good fit $(\chi 2 / \mathrm{df}=1.94$; $\mathrm{RMSEA}=0.05 ; \mathrm{SRMR}=0.04 ; \mathrm{CFI}=$ $0.98 ; \mathrm{NFI}=0.96 ; \mathrm{GFI}=0.97$; TLI $=0.97)$. The internal consistency was deemed good and Cronbach's $\alpha, \mathrm{CR}$, and AVE values were acceptable $(0.84,0.74$, and 0.52 , respectively). This scale was included in the parent-reported survey. Parents were asked to recall the past month and rate the items on a five-point scale ranging from 1 (never) to 5 (every day). Items regarding depression items included "At least one of my children has become isolated in their room," while items covering anxiety included "At least one of my children worries that something awful will happen to someone in the family." All items were reverse-coded.

\section{Statistical Analysis}

To investigate the relationships among the model variables, SPSS V26 software was used, and the path analysis model was evaluated using Amos 26 software with 5000 bootstrapped samples and a 95\% bias-corrected confidence interval. The method used in the path analysis was a maximum likelihood estimation. The multivariate normality assumption was checked, and normal distribution was accepted where skewness and kurtosis values were below two and seven, respectively (Curran et al., 1996). We investigated the goodness of fit for the proposed model based on the work of Hu and Bentler (1999), where the cutoff values for the goodnessof-fit index (GFI), comparative fit index (CFI), normed fit index (NFI), and Tucker-Lewis index (TLI) were $>0.95$; RMSEA were $<0.06$; SRMR were $<0.08$.

\section{Results}

Table 1 shows the results of Pearson's correlation coefficient, which indicate that there was a significant positive correlation between social distancing and parents' activities with their children $(r=0.19 ; p=0.02)$ as well as their coping strategies $(r=0.22 ; p<0.001)$. Further, parents' mental health was significantly positively correlated with parents' activities with their children $(r=0.46 ; p<0.001)$, children's mental health $(r=0.50 ; p<0.001)$, and parents' coping strategies $(r=0.68 ; p<0.001)$. Parents' activities with their children were also significantly positively correlated with children's mental health $(r=0.26 ; p<0.001)$ and parents' 
coping strategies $(r=0.55 ; p<0.001)$. Lastly, children's mental health was significantly positively correlated with parents' coping strategies $(r=0.36 ; p<0.001)$.

Figure 1 shows the results of path analysis, which indicate the significant direct and indirect relationships among the variables used in the model. Social distancing practices $(r=0.08, p=$ $0.002 ; 95 \%$ CI $[0.132,041])$ indirectly influenced children's mental health $(\mathrm{ChMH})$ through parents' activities with their children (PA), parents' coping strategies (CSP), and parents' mental health (MHP). Moreover, social distancing practices $(r=0.16, p=0.002 ; 95 \% \mathrm{CI}$ $[0.235,0.073])$ were indirectly related to MHP through PA and CSP.

PA $(r=0.25, p=0.002 ; 95 \%$ CI $[0.312,0.184])$ were indirectly related to $\mathrm{ChMH}$ through MHP and CSP. Additionally, PA $(r=0.13, p=0.024 ; 95 \%$ CI $[0.229,023])$ had a direct effect on MHP and indirect effect $(r=0.33, p=0.002 ; 95 \%$ CI [0.403, 0.251]) through CSP.

CSP $(r=0.32, p=0.002 ; 95 \%$ CI $[0.369,0.245)])$ had an indirect impact on ChMH via MHP. In addition, CSP had a direct impact ( $r=0.60, p=0.002 ; 95 \%$ CI [0.697, 0.499]) on MHP. Standardized estimates of total, direct, and indirect effects on MHP and ChMH are summarized in Table 2.

The model explains $29 \%$ of ChMH, $47 \%$ of MHP, $33 \%$ of CSP, and $4 \%$ of PA. Moreover, the model's goodness-of-fit indices were satisfactory $(\chi 2 / d f=0.48, \mathrm{RMSEA}=0.00, \mathrm{SRMR}=$ $0.01, \mathrm{CFI}=0.99, \mathrm{NFI}=0.99, \mathrm{GFI}=0.99, \mathrm{TLI}=0.99)$.

\section{Discussion}

This study aimed to investigate the effects of social distancing practices on both parents' and children's mental health during the COVID-19 pandemic. Moreover, it aimed to explore the role of parent's activities with their children as well as parents' coping strategies.

According to the correlation coefficients and path analysis results, social distancing practices had a significant indirect effect on both parents' and children's mental health through parents' activities with their children and parents' coping strategies. This implies that parents' coping skills and engagement in activities with their children played a significant role in promoting the mental health of both parents and children.

The results showed clearly that social distancing practices were significantly positively correlated with both parents' activities with their children and parents' coping strategies. This indicates that social distancing practices in Qatar motivated parents to develop activities for their children, to engage with them in such activities, as well as to use their coping strategies.

Table 1 Means, standard deviations, and correlations

\begin{tabular}{llllll}
\hline & 1 & 2 & 3 & 4 & 5 \\
\hline 1: SD & & & & \\
2: MHP & 0.107 & & & \\
3: PA & $0.190^{* *}$ & $0.461^{* *}$ & & \\
4: ChMH & 0.071 & $0.503^{* *}$ & $0.262^{* *}$ & & 3.55 \\
5: CSP & $0.220^{* *}$ & $0.676^{* *}$ & $0.547^{* *}$ & $0.361^{* *}$ & \\
Mean & 4.44 & 4.03 & 3.74 & 4.27 & 0.92 \\
Standard deviation & 0.49 & 0.84 & 0.71 & 0.63 & \\
\hline
\end{tabular}

$S D=$ social distancing; $M H P=$ mental health of parents; $P A=$ parents' activities with children; $C h M H=$ children's mental health; $C S P=$ coping strategies of parents

$* p<0.05 ; * * p<0.001$ 


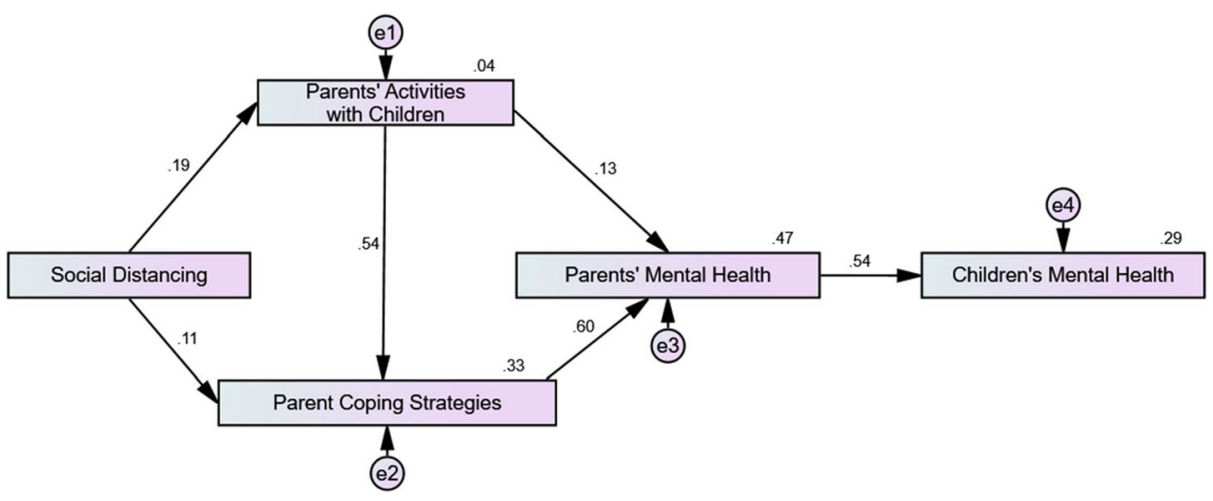

Fig. 1 Results of path analysis with effects of social distancing practices on parents' and children's mental health

These results are consistent with those of Brammer (1992), who reported that when individuals encounter a sudden transition in their life, learned coping skills help them handle stressful situations. Moreover, Fares et al. (2016) revealed that exposure to stressful conditions encourages individuals to develop activities to help them cope with these conditions.

Our results also showed that parental activities with their children were significantly positively correlated with parents' coping strategies. This means that parents who develop and engage in activities with their children are more likely to have coping skills that enable them to handle stressful circumstances.

Additionally, our results showed that parental activities with their children were significantly positively correlated with children's mental health. This indicates that activities that engage both parents and their children (e.g., playing with them at home) are more likely to enhance children's mental health. These results are consistent with those of Wang and SheikhKhalil (2014), who reported that parents' home-based involvement enhances children's mental

Table 2 Standard estimates of total, direct, and indirect effects on MHP and ChMH

\begin{tabular}{|c|c|c|c|c|}
\hline & Effect & Sig & Upper & Lower \\
\hline $\mathrm{SD} \rightarrow \mathrm{ChMH}$ (total effects) & 0.085 & 0.002 & 0.132 & 0.041 \\
\hline $\mathrm{SD} \rightarrow \mathrm{ChMH}$ (indirect effects) & 0.085 & 0.002 & 0.132 & 0.041 \\
\hline $\mathrm{SD} \rightarrow \mathrm{MHP}$ (total effects) & 0.158 & 0.002 & 0.235 & 0.073 \\
\hline $\mathrm{SD} \rightarrow \mathrm{MHP}$ (indirect effects) & 0.158 & 0.002 & 0.235 & 0.073 \\
\hline $\mathrm{SD} \rightarrow \mathrm{PA}$ (total effects) & 0.194 & 0.003 & 0.305 & 0.073 \\
\hline $\mathrm{SD} \rightarrow \mathrm{PA}$ (direct effects) & 0.194 & 0.003 & 0.305 & 0.073 \\
\hline $\mathrm{SD} \rightarrow \mathrm{CSP}$ (total effects) & 0.220 & 0.002 & 0.328 & 0.102 \\
\hline $\mathrm{SD} \rightarrow \mathrm{CSP}$ (direct effects) & 0.115 & 0.022 & 0.212 & 0.018 \\
\hline $\mathrm{SD} \rightarrow \mathrm{CSP}$ (indirect effects) & 0.105 & 0.003 & 0.172 & 0.039 \\
\hline $\mathrm{PA} \rightarrow \mathrm{MHP}$ (total effects) & 0.460 & 0.004 & 0.312 & 0.184 \\
\hline $\mathrm{PA} \rightarrow \mathrm{MHP}$ (direct effects) & 0.133 & 0.024 & 0.229 & 0.023 \\
\hline $\mathrm{PA} \rightarrow \mathrm{MHP}$ (indirect effects) & 0.326 & 0.002 & 0.403 & 0.251 \\
\hline $\mathrm{PA} \rightarrow \mathrm{ChMH}$ (total effects) & 0.248 & 0.002 & 0.312 & 0.184 \\
\hline $\mathrm{PA} \rightarrow \mathrm{ChMH}$ (indirect effects) & 0.248 & 0.002 & 0.312 & 0.184 \\
\hline $\mathrm{CSP} \rightarrow \mathrm{MHP}$ (total effect) & 0.601 & 0.002 & 0.697 & 0.499 \\
\hline $\mathrm{CSP} \rightarrow \mathrm{MHP}$ (direct effect) & 0.601 & 0.002 & 0.697 & 0.499 \\
\hline $\mathrm{CSP} \rightarrow \mathrm{ChMH}$ (total effect) & 0.324 & 0.002 & 0.369 & 0.245 \\
\hline $\mathrm{CSP} \rightarrow \mathrm{ChMH}$ (indirect effect) & 0.324 & 0.002 & 0.369 & 0.245 \\
\hline
\end{tabular}

$S D=$ social distancing; $M H P=$ mental health of parents; $P A=$ parents activities with children; $C h M H=$ children's mental health; $C S P=$ coping strategies of parents 
health. This also confirms the results of Roeters and Van Houdt (2019), who found that fathers' engagement in children's activities promotes children's mental health. Moreover, our results demonstrate that parent-child activities were positively correlated with parents' mental health. As the interactions between children and parents are mutual (Ray, 2008) and the relationship between parents and children improves through joint activities, we conclude that the more parents engage in activities with their children, the more they enhance the level of their own mental health.

Parents' coping strategies were associated with their level of mental health. These results coincide with prior research (e.g., Tsaras et al., 2018), who declared that coping strategiessuch as problem-solving and social support - are associated with mental health. It is worth noting that the results of the current study showed that parents' mental health was significantly positively correlated with their children's mental health. This indicates that mentally healthy parents tend to maintain good relationships with their children. These results are consistent with those of previous research (e.g., Ryan et al., 2017; Parfitt et al., 2013; Mensah and Kiernan, 2010).

According to Stafford and Chiteji (2012), healthy parents' behavior toward their children could be transmitted across generations and affect a child's behavior in the future. Therefore, parents who adhere to social distancing practices and engage with their children in various activities at home are more likely to have a good level of mental health, which can enhance the mental health of their children. Children could benefit from this parenting approach in the future, as they could probably be able to do the same thing for their own children.

Since Qatar is an Arabic society where relationships among family members are highly valued, parents have a strong obligation to meet their children's needs (Al-Kaabi, 2010). Therefore, we conclude that, under stressful circumstances, parents' coping skills and willingness to engage in activities with their children mitigate the potential stress resulted from social isolation.

The findings of this study provide an important conclusion: living under stressful circumstances like the COVID-19 pandemic and the related restrictions of social distancing practices do not only have negative effects on individuals' mental health, but that can also result in positive outcomes. The current study establishes that individuals can benefit from stressful situations by developing useful coping strategies to maintain good mental health. Moreover, it also illustrated the important role of parents' coping strategies and involvement in their children's activities, which enhance both parents' and children's mental health.

Based on these results, healthcare providers and policymakers in the healthcare sector are recommended to develop and implement awareness campaigns to show parents how to benefit from stressful situations by developing and engaging in family activities that enhance mental health. Moreover, healthcare providers and other stakeholders concerned with mental health in the community are recommended to establish training platforms to educate parents about coping strategies that can be used to handle stressful situations.

Our study has certain limitations. First, the study targeted only Arab families who reside in Qatar; therefore, the sample may not be representative of all nationalities living in Qatar. Second, although data were collected randomly, $95 \%$ of the respondents held a college degree or higher; therefore, the sample may be biased due to invariance in the education level. Third, self-reported answers may be biased due to social desirability.

To conclude, although several studies have demonstrated the negative consequences of social distancing practices during COVID-19 (e.g., Pfefferbaum \& North, 2020; Rajkumar, 2020), the current study revealed the positive impact of these practices when people possess the appropriate coping skills. Thus, the current study empirically proved that parents can 
benefit from stressful situations by improving their coping skills and creating activities to enhance their mental health and that of their children. We suggest replicating the current study in the future with different nationalities to discover what type of coping strategies parents use to co-exist with their children during stressful conditions.

Authors' Contributions The authors were solely responsible for the entire work, including the study conception and design, material preparation, data collection and analysis, and writing of the manuscript.

\section{Declarations}

Conflict of Interest The authors declare there is no conflict of interest.

Ethical Approval The study was approved by the institutional review boards of the Doha Institute for Graduate Studies (Decision No. DI-IRB-2020-S65). The study was performed in accordance with the ethical standards as laid down in the 1964 Declaration of Helsinki.

\section{References}

A Wilder-Smith, M. D., D O Freedman, M. D. (2019). Isolation, quarantine, social distancing and community containment: pivotal role for old-style public health measures in the novel coronavirus (2019-nCoV) outbreak. Journal of Travel Medicine, 27(2), taaa020. https://doi.org/10.1093/jtm/taaa020.

Abdelrahman M. (2020). Personality traits, risk perception, and protective behaviors of Arab residents of Qatar during the COVID-19 pandemic. International Journal of Mental Health and Addiction, 1-12. Advance online publication. https://doi.org/10.1007/s11469-020-00352-7

Al-Kaabi, I. (2010). The socio-family and care staff opinion of services and role of children with special needs in Qatar. International Journal of Business and Social Science, 1(3).

Al-Kaabi, N., Selim, N. A. A., Singh, R., Almadahki, H., \& Salem, M. (2017). Prevalence and determinants of depression among Qatari adolescents in secondary schools. Family Medicine \& Medical Science Research, 6(3).

Bayham, J., \& Fenichel, E. P. (2020). Impact of school closures for COVID-19 on the US health-care workforce and net mortality: a modelling study. The Lancet Public Health, 5(5), e271-e278. https://doi.org/10.1016/ S2468-2667(20)30082-7.

Brammer, M. (1992). Coping with life transitions. International Journal for the Advancement of Counselling, 15 , 239-253. https://doi.org/10.1007/BF02449903.

Brooks, S. K., Webster, R. K., Smith, L. E., Woodland, L., Wessely, S., Greenberg, N., \& Rubin, G. J. (2020). The psychological impact of quarantine and how to reduce it: rapid review of the evidence. The Lancet.

Cai, W., Lian, B., Song, X., Hou, T., Deng, G., \& Li, H. (2020). A cross-sectional study on mental health among health care workers during the outbreak of corona virus disease. Asian Journal of Psychiatry, 51, 102111. https://doi.org/10.1016/j.ajp.2020.102111.

Carver, C. (1997). You want to measure coping but your protocol too long: consider the brief cope. International Journal of Behavioral Medicine, 4, 92-100. https://doi.org/10.1207/s15327558ijbm0401_6.

Chen, Q., Liang, M., Li, Y., Guo, J., Fei, D., \& Wang, L. (2020a). Mental health care for medical staff in China during the COVID-19 outbreak. Lancet Psychiatry, 7, e15-e16.

Chen, Y., Zhou, H., Zhou, Y., \& Zhou, F. (2020b). Prevalence of self-reported depression and anxiety among pediatric medical staff members during the COVID-19 outbreak in Guiyang. Psychiatry Res;288. https://doi. org/10.1016/j.psychres.2020.113005.

Christofferson, J. L., Okonak, K., Kazak, A. E., Pierce, J., Kelly, C., Schifano, E., Sciolla, J., Deatrick, J. A., \& Alderfer, M. A. (2020). Family consequences of potentially traumatic pediatric medical events: Implications for traumainformed care. Journal of Family Psychology, 34(2), 237-246. https://doi.org/10.1037/fam0000597

Clemens, J., \& Veuger, S. (2020). Implications of the Covid-19 pandemic for state government tax revenues (No. w27426). National Bureau of Economic Research.

Cui, J., Li, F. \& Shi, Z. L. (2019). Origin and evolution of pathogenic coronaviruses. Nature Reviews Microbiology 17, 181-192. https://doi.org/10.1038/s41579-018-0118-9. 
Cui, Y., Li, Y., \& Zheng, Y. (2020a). Mental health services for children in China during the COVID-19 pandemic: results of an expert-based national survey among child and adolescent psychiatric hospitals. European Child and Adolescent Psychiatry, 29, 743-748. https://doi.org/10.1007/s00787-020-01548-x.

Cui, Y., Li, Y., Zheng, Y., \& Chinese Society of Child \& Adolescent Psychiatry. (2020b). Mental health services for children in China during the COVID-19 pandemic: results of an expert-based national survey among child and adolescent psychiatric hospitals. European Child \& Adolescent Psychiatry, 29(6), 743-748. https://doi.org/10.1007/s00787-020-01548-x.

Curran, J., West, G., \& Finch, F. (1996). The robustness of test statistics to nonmorality and specification error in confirmatory factor analysis. Psychological Methods, 1, 16-29. https://doi.org/10.1037/1082-989X.1.1.16.

Duan, L., \& Zhu, G. (2020). Psychological interventions for people affected by the COVID-19 epidemic. The Lancet Psychiatry, 7, 300-302. https://doi.org/10.1016/S2215-0366(20)30073-0.

Fares, J., Al Tabosh, H., Saadeddin, Z., El Mouhayyar, C., \& Aridi, H. (2016). Stress, burnout, and coping strategies in preclinical medical students. Journal of Medical Sciences, 8, 75-81. https://doi.org/10.4103/ 1947-2714.177299.

Fegert, H., \& Kölch, M. (2017). Poverty hits children first? A child and adolescent psychiatric perspective on effects of the economic crisis. Die Psychiatrie, 14(2), 67-74.

Fegert, M., Berthold, O., Clemens, V., \& Kölch, M. (2020). COVID-19-Pandemie: Kinderschutz ist systemrelevant. Deutsches Ärzteblatt, 117, 703-707.

Galea, S., Merchant, R. M., \& Lurie, N. (2020). The mental health consequences of COVID-19 and physical distancing: the need for prevention and early intervention. JAMA Internal Medicine, 180(6), 817-818.

García, F. E., Barraza-Peña, C. G., Wlodarczyk, A., Alvear-Carrasco, M., \& Reyes-Reyes, A. (2018). Psychometric properties of the Brief-COPE for the evaluation of coping strategies in the Chilean population. Psicologia: Reflexão e Crítica, 31(1), 22.

Goyal, P., Choi, J. J., Pinheiro, L. C., Schenck, E. J., Chen, R., Jabri, A., ... \& Safford, M. M. (2020). Clinical characteristics of Covid-19 in New York city. New England Journal of Medicine, 382(24), 2372-2374.

Heckman, P. R., Kuhn, F. R., Meerlo, P., \& Havekes, R. (2020). A brief period of sleep deprivation negatively impacts the acquisition, consolidation, and retrieval of object-location memories. Neurobiology of Learning and Memory, 175, 107326.

Hu, T., \& Bentler, M. (1999). Cutoff criteria for fit indexes in covariance structure analysis: conventional criteria versus new alternatives. Structural Equation Modeling: A Multidisciplinary Journal, 6, 1-55. https://doi.org/ 10.1080/10705519909540118.

Jacobson, C., Lekkas, D., Price, G., Heinz, V., Song, M., O’Malley, A., \& Barr, P. (2020). Flattening the mental health curve: COVID-19 stay-at-home orders result in alterations in mental health search behavior in the United States. Journal of Medical Internet Research: Mental Health, 7, 1-32. Retrieved from https://doi.org/10.2196/19347

Jones, M.(2020). Covid-19 in Qatar: Well versed in crisis management. Gulf insights $N^{\circ} 21$, Covid-19 in the Gulf special coverage.

Kang, L., Li, Y., Hu, S., Chen, M., Yang, C., \& Yang, B. (2020). The mental health of medical workers in Wuhan, China dealing with the 2019 novel coronavirus. The Lancet Psychiatry, 7, 14. https://doi.org/10. $1016 / \mathrm{S} 2215-0366(20) 30047-\mathrm{X}$.

Keyes, M. (2005). Mental illness and/or mental health? Investigating axioms of the complete state model of health. Journal of Consulting and Clinical Psychology, 73, 539-548. https://doi.org/10.1037/0022-006X.73.3.539.

Kline, R. (1998). Principles and practice of structural equation modeling. The Guilford Press.

Lau, H., Khosrawipour, V., Kocbach, P., Mikolajczyk, A., Schubert, J., Bania, J., \& Khosrawipour, T. (2020). The positive impact of lockdown in Wuhan on containing the COVID-19 outbreak in China. Journal of travel medicine, 27(3), taaa037.

Liem, A., Wang, C., Wariyanti, Y., Latkin, C., \& Hall, B. (2020). The neglected health of international migrant workers in the COVID-19 epidemic. The Lancet Psychiatry, 7, 20. https://doi.org/10.1016/S2215-0366(20)30076-6.

Liu, J. J., Bao, Y., Huang, X., Shi, J., \& Lu, L. (2020). Mental health considerations for children quarantined because of COVID-19. Lancet Child Adolesc Health, S2352-4642(20), 30096-30091.

Marroquín, B., Vine, V., \& Morgan, R. (2020). Mental health during the COVID-19 pandemic: Effects of stayat-home policies, social distancing behavior, and social resources. Psychiatry Research, 293, 113419.

Matsubayashi, T., Sekijima, K., \& Ueda, M. (2020). Government spending, recession, and suicide: evidence from Japan. BMC Public Health, 20, 243.

Mensah, F., \& Kiernan, K. (2010). Parents' mental health and children's cognitive and social development. Social Psychiatry and Psychiatric Epidemiology, 45, 1023-1035. https://doi.org/10.1007/s00127-009-0137-y.

Ministry of public Health.(2020). Statement of the Government Communications Office about the State of Qatar taking a package of decisions to combat Coronavirus, https:/www.moph.gov.qa/arabic/mediacenter/News/ Pages/NewsDetails.

Nanshan Chen, Min Zhou, Xuan Dong. (2020). Epidemiological and clinical characteristics of 99 cases of 2019 novel coronavirus pneumonia in Wuhan, China: a descriptive study; 395(10223):507-513. 
Omrani, A., Almaslamani, M., Daghfal, J., Alattar, R., Elgara, M., Shaar, S., Ibrahim, T., Zaqout,A., Bakdach, D., Akkari, A., Baiou, A., Alhariri, B., Elajez, R., Husain, A., Badawi, M., Ben Abid, F., Abu Jarir, S., Abdalla, S., Kaleeckal, A., Choda, K., Chinta, V., Sherbash, M., Al-Ismail,K., Abukhattab, M., Hssain, A., Coyle, P., Bertollini, R., Frenneaux, M., Al Khal, A., Al Kuwari, H. (2020). The First Consecutive 5000 Patients with COVID-19 in Qatar; a Nation-wide Cohort Study. https://doi.org/10.1101/2020.07.15. 20154690

Parfitt, Y., Pike, A., \& Ayers, S. (2013). The impact of parents' mental health on parent-baby interaction: a prospective study. Infant Behavior and Development, 36, 599-608. https://doi.org/10.1016/j.infbeh.2013.06.003.

Pfefferbaum, B., \& North, C. (2020). Mental health and the Covid-19 pandemic. New England Journal of Medicine, 383, 510-512. https://doi.org/10.1056/NEJMp2008017.

Prestia, D., Pozza, A., \& c Olcese, M., Escelsior, A., Dettore, D., and Amore, M. (2020). The impact of the COVID-19 pandemic on patients with OCD: Effects of contamination symptoms and remission state before the quarantine in a preliminary naturalistic study. Psychiatry Research, 291, 113213.

Primack, B., Carroll, M., McNamara, M., Klem, M., King, B., \& Rich, M. (2012). Role of video games in improving health-related outcomes: a systematic review. American Journal of Preventive Medicine, 42, 630-638. https://doi.org/10.1016/j.amepre.2012.02.023.

Rajkumar, R. (2020). COVID-19 and mental health: a review of the existing literature. Asian Journal of Psychiatry, 52, 1-5. https://doi.org/10.1016/j.ajp.2020.102066.

Ray, D. (2008). Impact of play therapy on parent-child relationship stress at a mental health training setting. British Journal of Guidance and Counselling, 36, 165-187. https://doi.org/10.1080/03069880801926434.

Remuzzi, A., \& Remuzzi, G. (2020). COVID-19 and Italy: What next? The Lancet, 395, 1225-1228. https://doi. org/10.1016/S0140-6736(20)30627-9.

Roeters, A., \& van Houdt, K. (2019). Parent-child activities, paid work interference, and child mental health. Family Relations, 68, 232-245. https://doi.org/10.1111/fare.12355.

Ryan, R., O'Farrelly, C., \& Ramchandani, P. (2017). Parenting and child mental health. London Journal of Primary Care, 9, 86-94. https://doi.org/10.1080/17571472.2017.1361630.

Shah, B., Harari, R., Ibrahim, H., Friedman, G., Thompson, C., Alviar, C., et al. (2020). ST-segment elevation in patients with Covid-19 — a case series. The New England Journal of Medicine, 382, 2478-2480. https://doi. org/10.1056/NEJMc2009020.

Stafford, F., \& Chiteji, N. (2012). Shaping health behavior across generations: evidence from time use data in the panel study of income dynamics and its supplements. Annals of economics and statistics, 105, 185-208.

Torales, J., O’Higgins, M., Mauricio, J., Maia, C., \& Ventriglio, A. (2020). The outbreak of COVID-19 coronavirus and its impact on global mental health. International Journal of Social Psychiatry, 66, 317320. https://doi.org/10.1177/0020764020915212.

Tsaras, K., Daglas, A., Mitsi, D., Papathanasiou, I., Tzavella, F., Zyga, S., \& Fradelos, E. (2018). A crosssectional study for the impact of coping strategies on mental health disorders among psychiatric nurses. Health Psychology Research, 6, 9-15. https://doi.org/10.4081/hpr.2018.7466.

Wang, M., \& Sheikh Khalil, S. (2014). Does parental involvement matter for student achievement and mental health in high school? Child Development, 85, 610-625. https://doi.org/10.1111/cdev.12153.

Wang, G., Zhang, Y., Zhao, J., Zhang, J., \& Jiang, F. (2020a). Mitigate the effects of home confinement on children during the COVID-19 outbreak. The Lancet, 395, 945-947. https://doi.org/10.1016/S01406736(20)30547-X.

Wang D, Hu B, Hu C.(2020b). Novel coronavirus-infected pneumonia in Wuhan, China. JAMA;e201585.

Wilkinson, N., Ang, R., \& Goh, D. (2008). Online video game therapy for mental health concerns: a review. International Journal of Social Psychiatry, 54, 370-382. https://doi.org/10.1177/0020764008091659.

World Health Organization. (2020). Novel coronavirus (2019-nCoV) situation report. Retrieved from https:// www.who.int/docs/default-source/coronaviruse/situation-reports/20201012-weekly-epi-update-9.pdf, Date: Oct 11, 2020, Date accessed: October 15, 2020.

Yang, X., Yu, Y., Xu, J., Shu, H., Liu, H., Wu, Y., ... \& Shang, Y. (2020). Clinical course and outcomes of critically ill patients with SARS-CoV-2 pneumonia in Wuhan, China: a single-centered, retrospective, observational study. The Lancet Respiratory Medicine, 8(5), 475-481.

Zu, Z., Jiang, M., Xu, P., Chen, W., Ni, Q., \& Lu, G. (2020). Coronavirus disease 2019 (COVID-19): a perspective from China. Radiology, 296, 15-25. https://doi.org/10.1148/radiol.2020200490.

Publisher's Note Springer Nature remains neutral with regard to jurisdictional claims in published maps and institutional affiliations. 